Supporting information for

\title{
Multimodal Plasmonic Assay of Copper (II) Ion via Stimuli-Responsive State Transformation of Silver Molecular Nanoparticles
}

Yang Chen, Danyang Yin, Yanyan Ma, Zijun Bie, and Zhen Liu*

State Key Laboratory of Analytical Chemistry for Life Science, School of Chemistry and Chemical Engineering, Nanjing University, Nanjing 210023, China

* Corresponding author. Email: zhenliu @ nju.edu.cn.

\section{Table of contents}

- Supplementary Figures

Figure S1 to Figure S7

- Supplementary Tables

Table S1 


\section{SUPPLEMENTARY DATA}
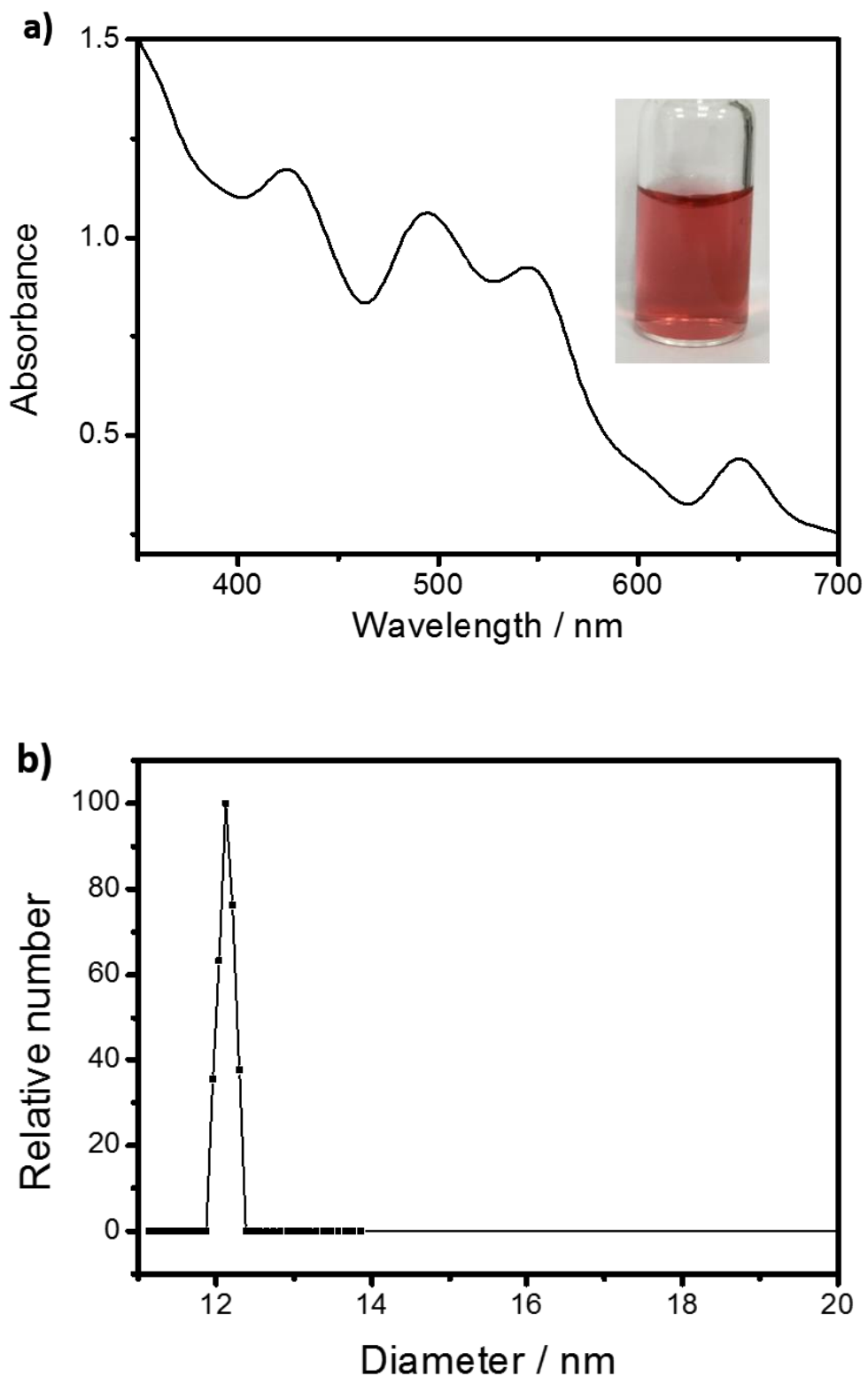


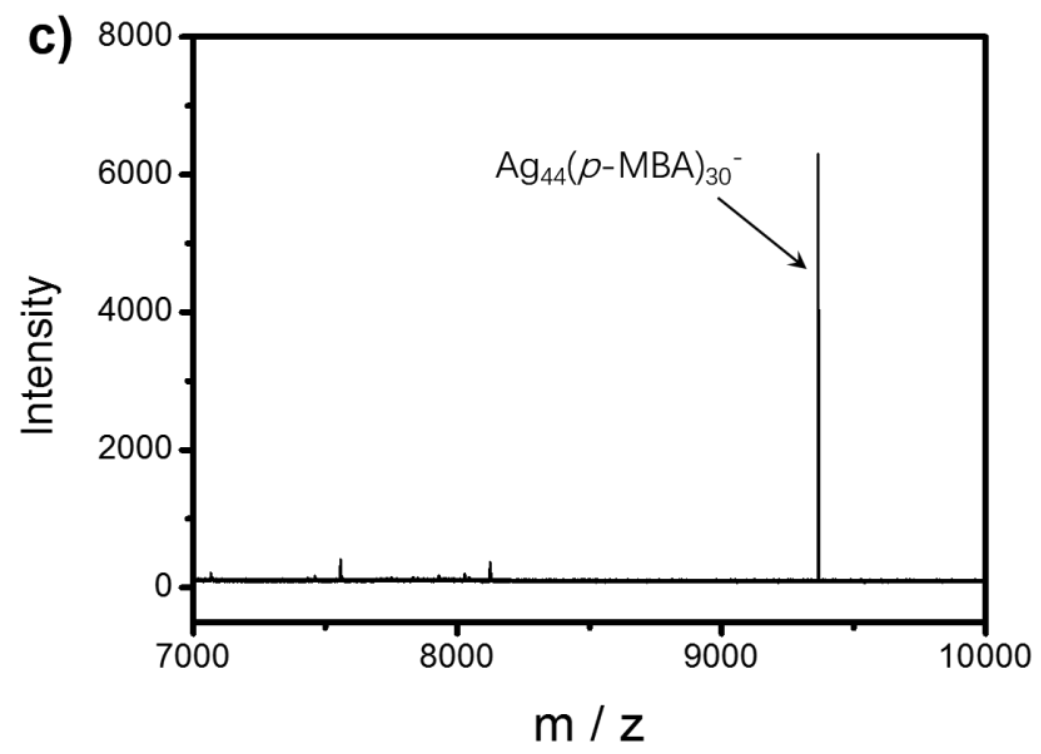

Figure S1. a) UV-Vis absorption spectra and photography (insert), b) DLS characterization as well as c) MALDI-TOF MS analysis of freshly made Ag MNPs (0.2 $\mu \mathrm{M}, 5 \%$ DMSO). 


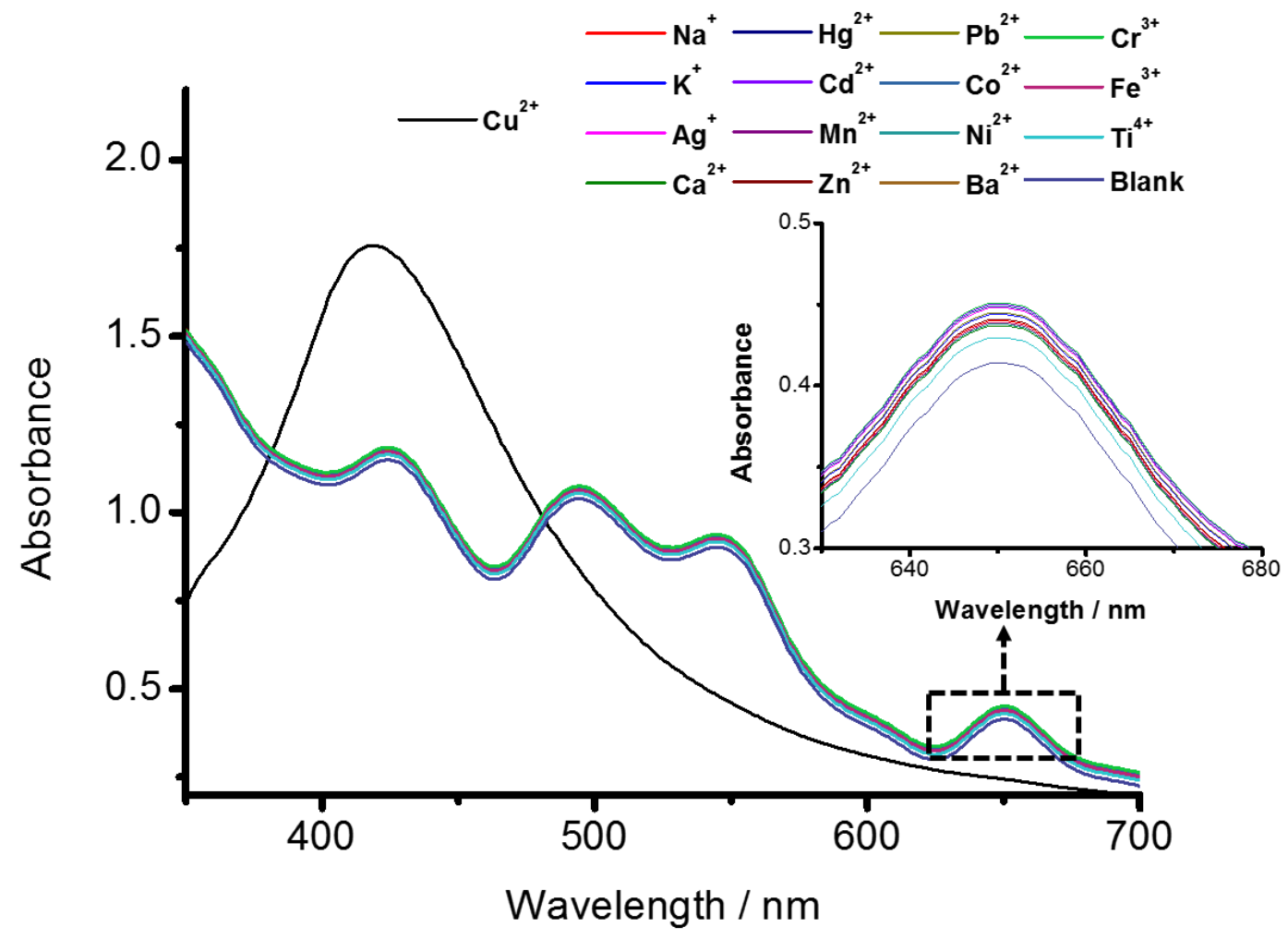

Figure S2. UV-vis absorption spectra of Ag MNPs (0.2 $\mu \mathrm{M} 5 \%$ DMSO) mixed with different metal ions at the concentration of $10^{-5} \mathrm{M}(5 \% \mathrm{DMSO})$. 

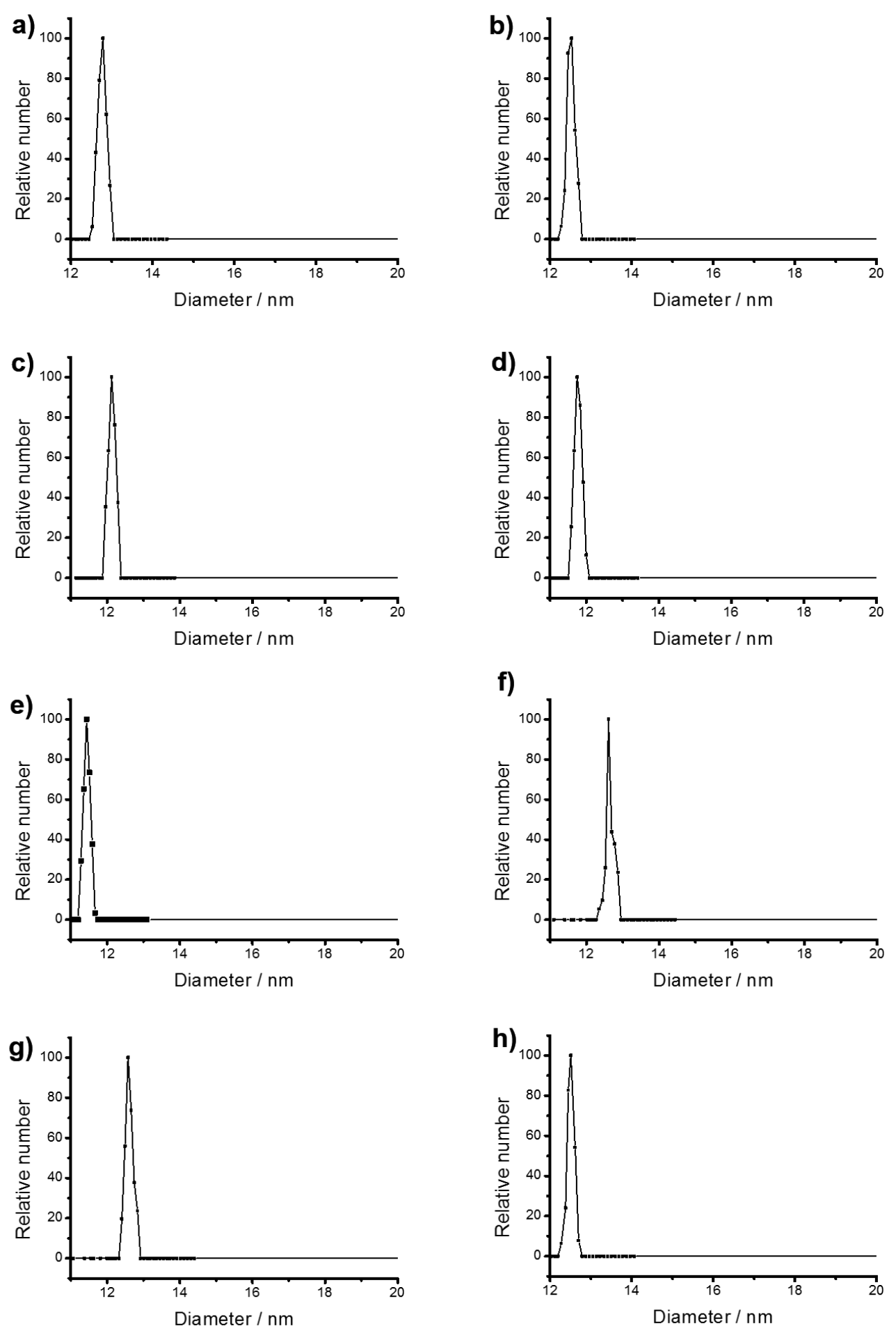

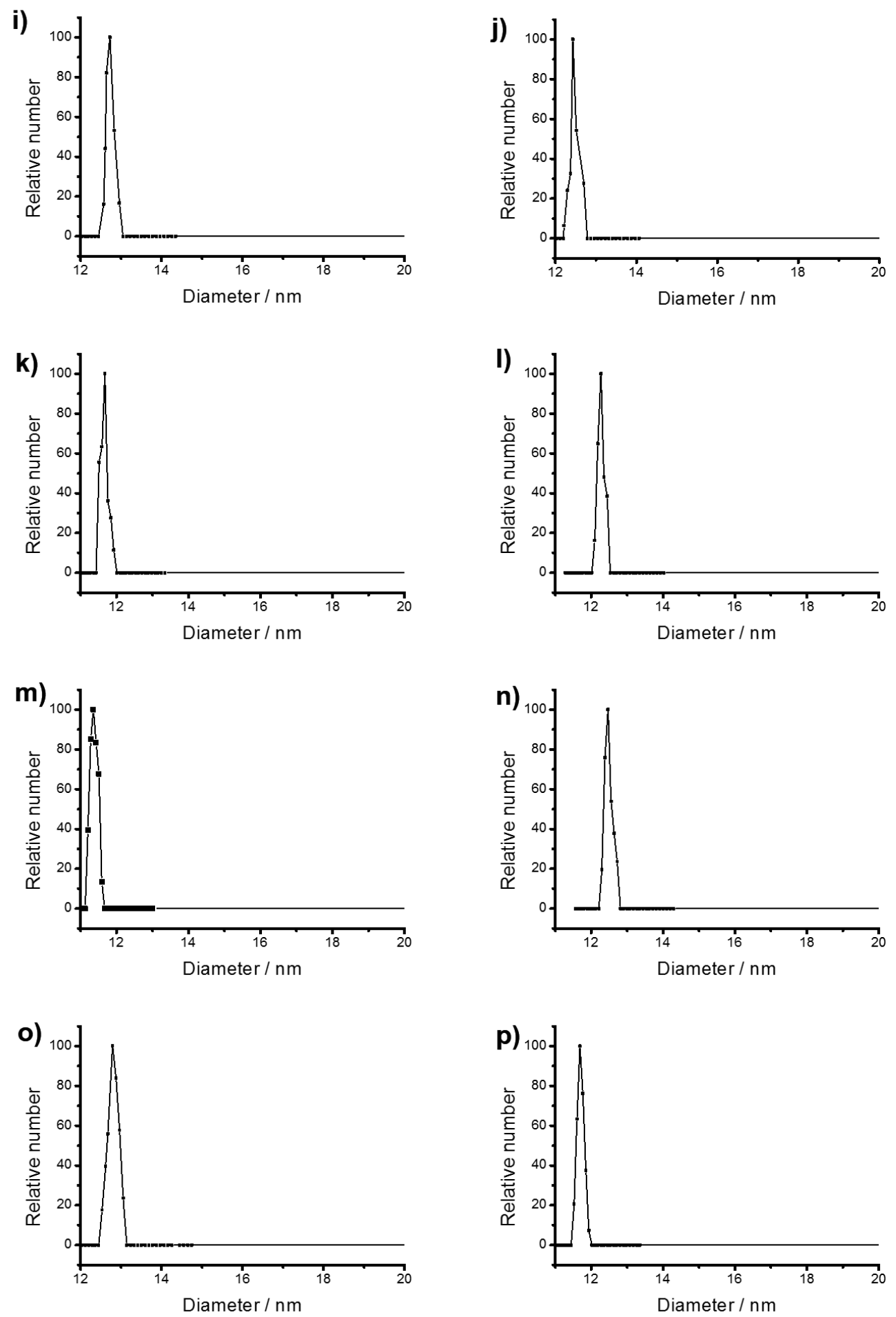


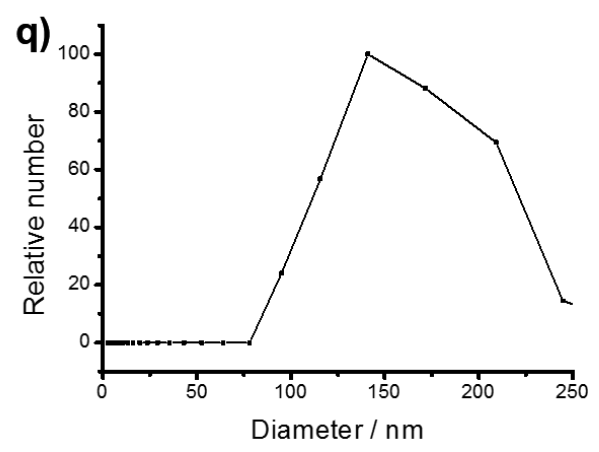

Figure S3. DLS characterization of $\operatorname{Ag}$ MNPs $(0.2 \mu \mathrm{M}, 5 \%$ DMSO $)$ mixed with different metal ions ( $\left.10^{-5} \mathrm{M}, 5 \% \mathrm{DMSO}\right)$. From a) to q): Blank, $\mathrm{Na}^{+}, \mathrm{K}^{+}, \mathrm{Ag}^{+}, \mathrm{Ca}^{2+}, \mathrm{Hg}^{2+}, \mathrm{Cd}^{2+}$, $\mathrm{Mn}^{2+}, \mathrm{Zn}^{2+}, \mathrm{Pb}^{2+}, \mathrm{Co}^{2+}, \mathrm{Ni}^{2+}, \mathrm{Ba}^{2+}, \mathrm{Cr}^{3+}, \mathrm{Fe}^{3+}, \mathrm{Ti}^{4+}$ and $\mathrm{Cu}^{2+}$. 

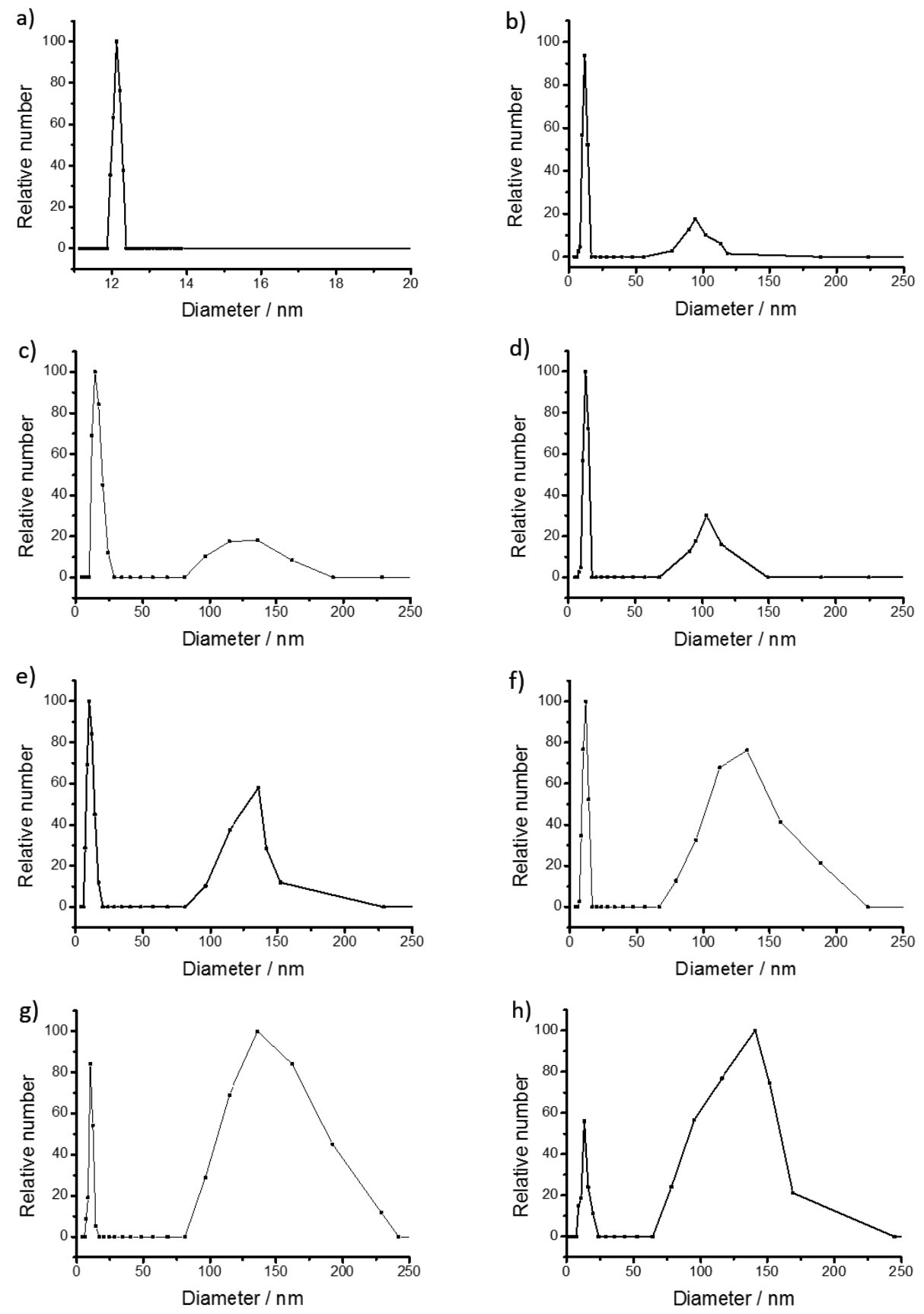

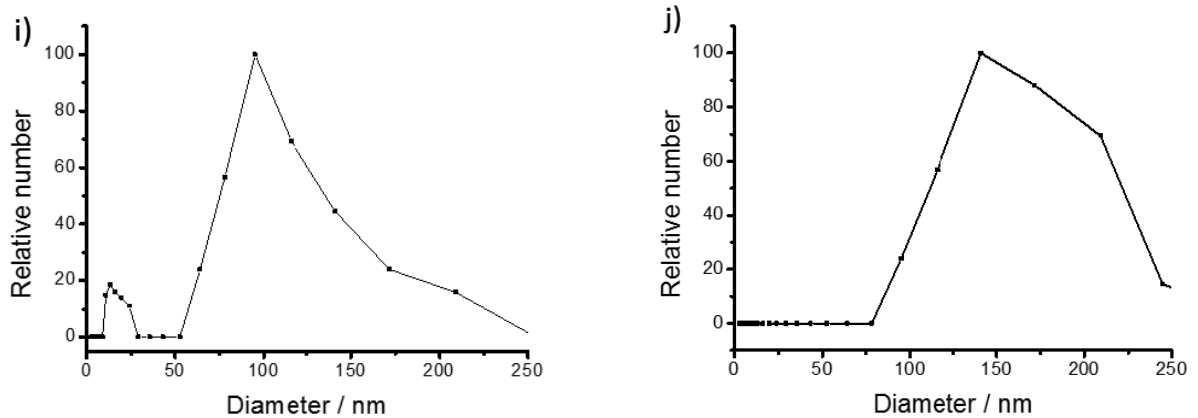

Figure S4. DLS characerization of Ag MNPs (0.2 $\mu \mathrm{M}, 5 \%$ DMSO) mixed with different concentration of $\mathrm{Cu}^{2+}$. a) to $\mathrm{j}$ ): $0,0.1,0.5,1,3,5,7,10,30,50 \mu \mathrm{M}$. 

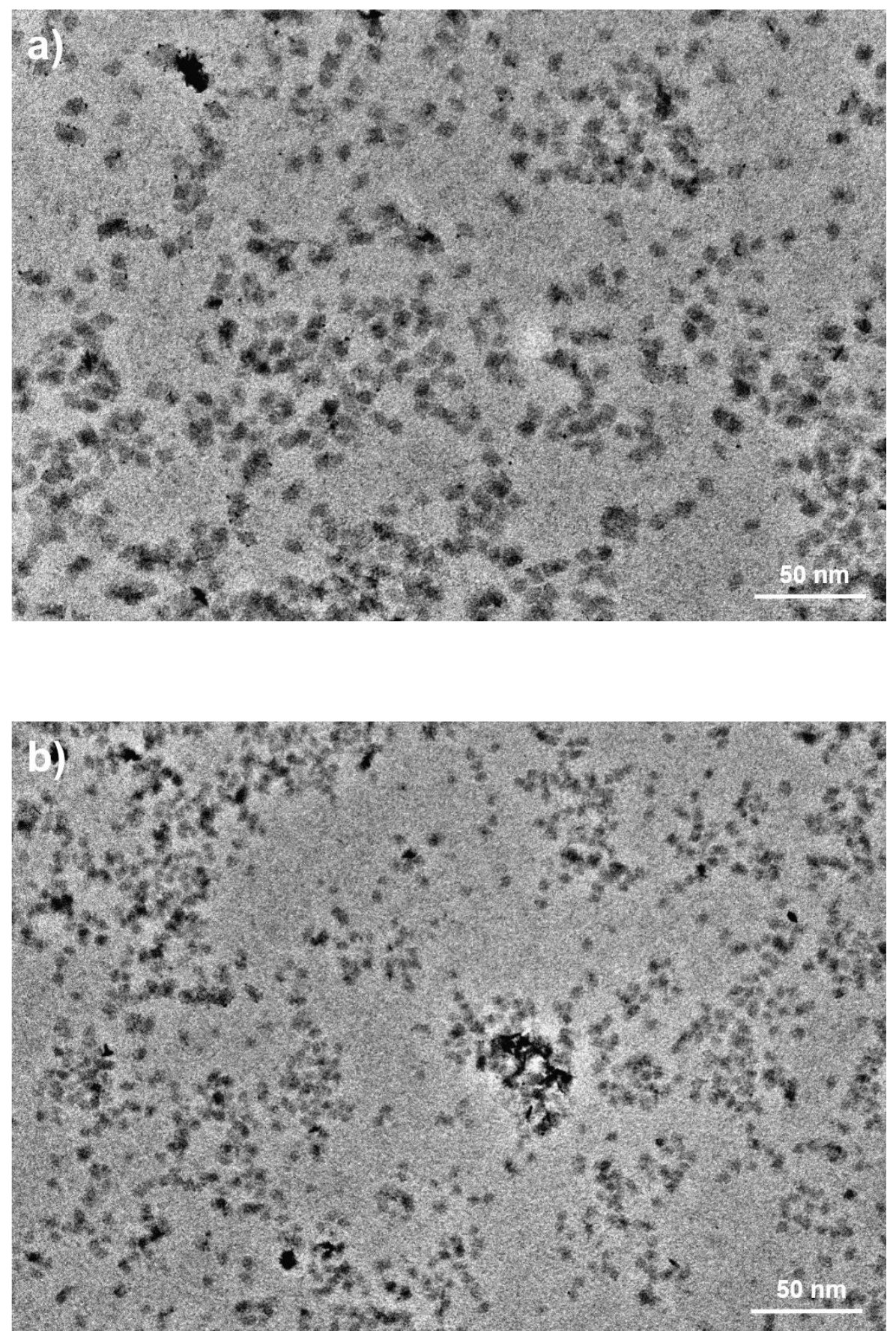


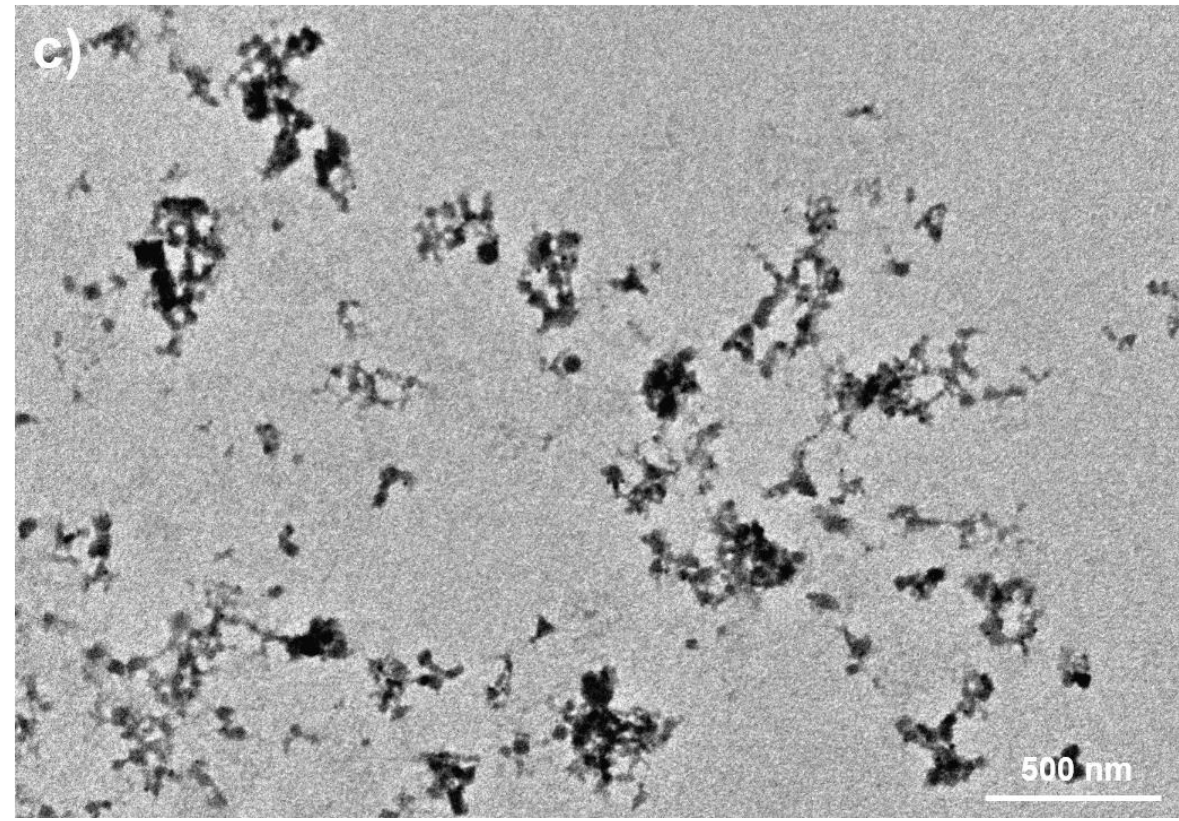

Figure S5. TEM image of a) freshly made $\mathrm{Ag}$ MNPs, b) $\mathrm{Ag}$ MNPs mixed with $0.5 \mu \mathrm{M} \mathrm{Cu}^{2+}$ and c) Ag MNPs mixed with $50 \mu \mathrm{M} \mathrm{Cu}^{2+}$. 


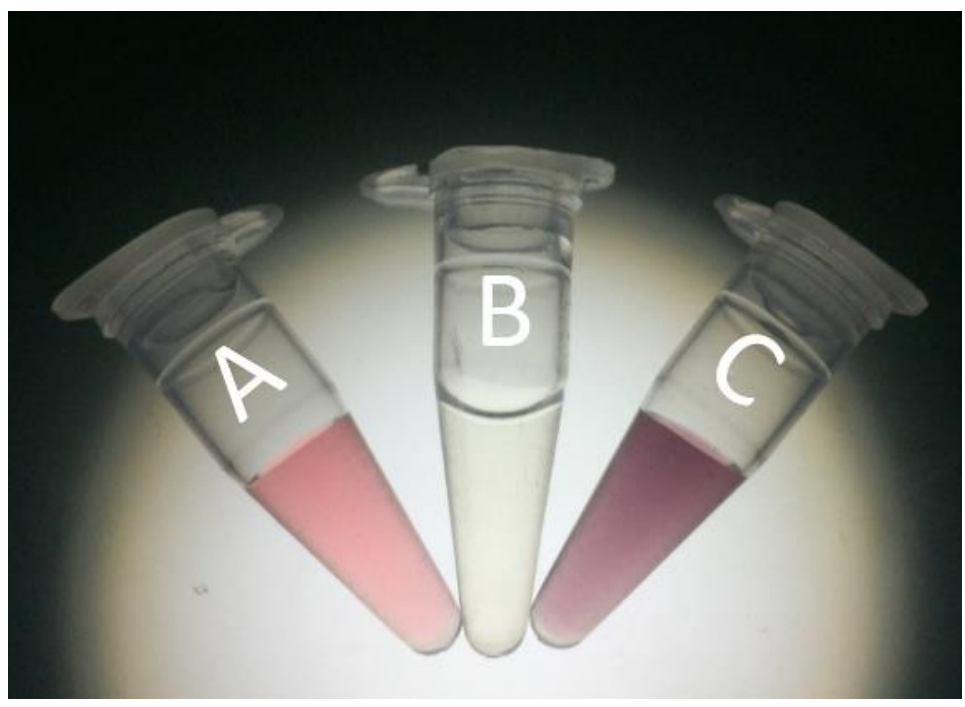

Figure S6. Photographs of (A) Ag MNPs (0.2 $\mu \mathrm{M}, 5 \%$ DMSO), (B) deproteinized human serum and (C) mixture of $\mathrm{A}$ and $\mathrm{B}$. 

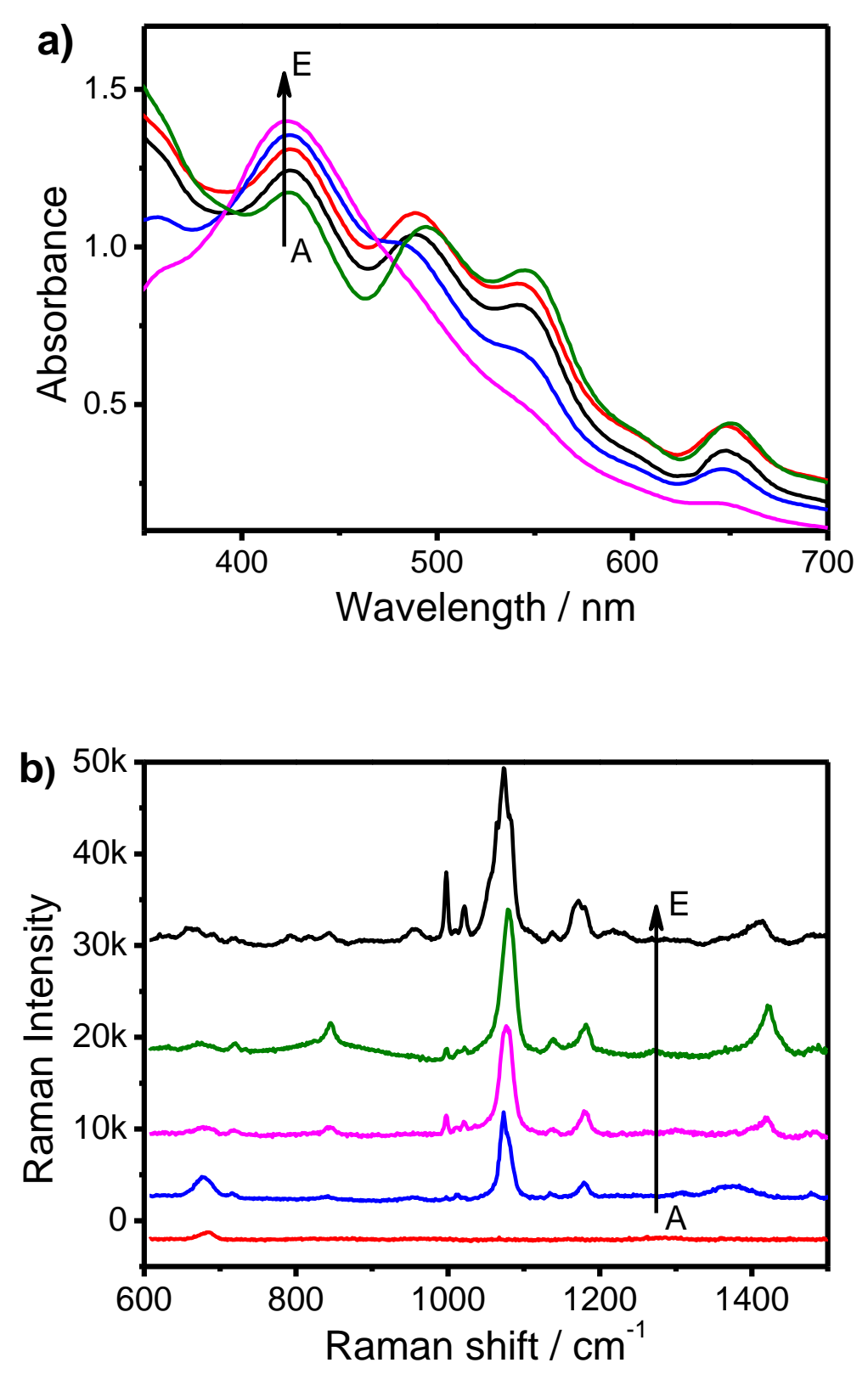

Figure S7. UV-Vis spectra for deproteinized human serum sample spiked with different $\mathrm{Cu}^{2+}$ concentrations (from A to E: $0,1,2,3 \mu \mathrm{M}$ ), b) SERS spectra for deproteinized human serum sample spiked with different $\mathrm{Cu}^{2+}$ concentrations (from A to E: $0,0.1,0.2,0.3 \mu \mathrm{M}$ ). 
Table S1. Mean diameter and percentage of plasmonic nanopartilces at different concentration of $\mathrm{Cu}^{2+}$.

\begin{tabular}{ccc}
\hline $\begin{array}{c}\text { Concentration of } \\
\mathrm{Cu}^{2+} / \mu \mathrm{M}\end{array}$ & Mean diameter of PNPs / nm & Percentage of PNPs / \% \\
\hline 0 & $12 \pm 0.3$ & 0 \\
0.1 & $91 \pm 11$ & 14 \\
0.5 & $104 \pm 32$ & 17 \\
1 & $120 \pm 19$ & 23 \\
3 & $133 \pm 17$ & 37 \\
5 & $136 \pm 63$ & 43 \\
7 & $141 \pm 52$ & 54 \\
10 & $145 \pm 47$ & 64 \\
30 & $144 \pm 55$ & 82 \\
50 & $150 \pm 84$ & 100 \\
\hline
\end{tabular}

